\title{
Pin Tract Infection after Uniplanar External Fixation of Open Fractures at a National, Teaching and Referral Hospital
}

\author{
R M Mohammed ${ }^{1}$, E O Atinga ${ }^{2}$, F C Sitati ${ }^{3}$, E.M Gakuya ${ }^{4}$ \\ ${ }^{1}$ Post-graduate student in Orthopaedic Surgery at the University of Nairobi, \\ Nairobi-Kenya. \\ ${ }^{2}$ Professor and Chair of Orthopaedic Surgery, Department of Orthopaedic \\ Surgery, University of Nairobi, Nairobi - Kenya. \\ ${ }^{3}$ Consultant Orthopaedic and Trauma Surgeon, and Lecturer, Department of \\ Orthopaedic Surgery, University of Nairobi, Nairobi - Kenya. \\ ${ }^{4}$ Consultant Orthopaedic and Trauma Surgeon, and Lecturer, Department of \\ Orthopaedic Surgery, University of Nairobi, Nairobi - Kenya. \\ Correspondence to: Fred Sitati. E mail: fredsitati@yahoo.com \\ https://dx.doi.org/10.4314/ecajs.v22i1.6
}

Background: Pin tract infection is the most common complication of external fixation accounting for $43 \%$ of complications. The presence of a pin tract infection leads to subsequent pin loosening and fixation failure. It also delays conversion of an external fixator to internal fixation until clearance of the infection is achieved. The incidence ofpin tract infections in our setting is not known. This study was aimed at determining the incidence and microbe profile of pin tract infection in patients who have undergone uniplanar external fixation following open fractures at Kenyatta National Hospital.

Methods: Consecutive sampling of patients who had undergone uniplanar external fixation at Kenyatta National Hospital (KNH) was done between September 2016 and December 2016. 73 patients were recruited. Data concerning presence of pin tract infection was collected. Patients with discharging sinuses had a culture and sensitivity done while those with major pin tract infection had immediate $x$-rays done to rule out radiological changes.

Results: Incidence of pin tract infection was $87.7 \%$ (64 of 73 patients). Staphylococcus aureus (30.2\%) and coagulase negative staphylococci (16.3\%) were the commonest causative organisms.

Conclusion: The incidence of pin tract infection after uniplanar external fixation is high. Better surgical technique and pin-site care is recommended. Staphylococcus aureus is the leading cause of pin site infection.

Introduction

The incidence of pin tract infections is highly variable. Parameswaran et al. in a level 1 trauma setting involving 285 patients with external fixators reported the incidence to be $11.2 \%$, his study was retrospective ${ }^{1}$. Schalamon et al studied the incidence of pin tract 


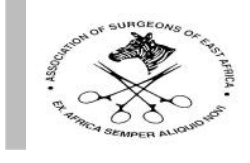

infections in 30 patients of the paediatric age group and found it to be $52 \%^{2}$. Aronson and Tursky in their study of femur fractures involving 42 children found an incidence of $85 \%{ }^{3}$. Regionally, a study by Jellis et al in Lusaka, Zambia, compared the rate of severe pin tract infection in HIV negative and positive patients, his sample size was 47 patients, and he found the rate of severe pin tract infection in HIV positive patients to be only $7 \%{ }^{4}$.

Most pin site infections are secondary to Staphylococcus aureus, followed by Pseudomonas aeruginosa. Other organisms that are common include Escherichia coli, Enterobacteraerogenes, Staphylococcus epidermidis and Acinetobacter ${ }^{5,6}$. Multiple factors are associated with the development of pin tract infections including the stability of the external fixator, the type of external fixator, the biomaterials used in the external fixator, the fracture pattern, pin insertion technique used, pin site care, duration of hospital stay and presence of co-morbid conditions such as presence of HIV in the patient.

There are several ways of classifying pin tract infections. Two examples arethe DAHL classification and the Checketts -Otterburn classification ${ }^{7}$. The latter is more commonly used as it also gives treatment guidelines.

\section{Patients and Methods}

This study was a prospective cross-sectional study, with consecutive sampling of patients. The study was conducted at the orthopedic wards and clinics of Kenyatta National Hospital (KNH). KNH is a metropolitan, tertiary, referral and teaching hospital in Nairobi. It has a 2000 bed capacity and is one of the two main referral hospitals in Kenya, also serving the greater East and Central Africa region.The study duration was between September 2016 and December 2016. The inclusion criteria were patients aged between $18-65$ years who have undergone uniplanar external fixation after open fractures and have given consent.

Exclusion criteria included patients with known co-morbidities conditions that may increase likelihood of infection such as human immunodeficiency virus infection, diabetes mellitus, liver failure, renal failure, tumours and smoking were excluded - these conditions were thought that they will increase the rate of pin tract infection.

The sample size calculated using Cochran formula (8) was 73. Data concerning presence and grade of pin tract infection was collected. A simplified form of Chicketts-Otterburn classification was used for grading. This is shown below.

Table 1. Grading of Pin Tract Infection

\begin{tabular}{|l|l|}
\hline Grade 1 & Redness, Tenderness and no Discharge \\
\hline Grade 2 & Presence of Discharge \\
\hline Grade 3 & As in no. 2 but with no Improvement on Oral Antibiotics \\
\hline Grade 4 & Pin Loosening Present \\
\hline Grade 5 & Radiographs Show Osteopenia around the Pins \\
\hline Grade 6 & Radiographs Show Sequestrum and Involucrum \\
\hline
\end{tabular}




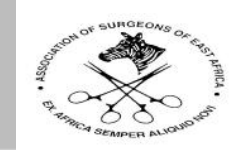

Follow up of patients was done on week 1 , week 2 and week 6.All patients with pus discharge had a pus swab for culture and sensitivity.

Method of obtaining a pus swab: the area around the infected pin was cleaned with normal saline to remove excess debris or excess necrotic tissue. Excess normal saline after the cleaning process was then removed using sterile gauze. Gloves were changed and sterile ones used. A pus swab was squeezed in between the pin site and the surrounding soft tissue. The aim was to obtain soft tissue exudates from the site of the pins. The swab was placed in Amies transport medium and sent to the lab within 1 hour of collection.

Pus swabs taken were incubated at 37 degrees Celsius for $16-18$ hours. Both aerobic and anaerobic cultures were done. Aerobic culture medium used was the Sheep Blood Agar or MacConkey agar. Anaerobic cultures were done using Wilkins Chalgren Amikacin Agar Positive aerobic and anaerobic cultures were tested for sensitivity to various antibiotics. All patients had a check $x$-ray done 6 weeks post external fixation to rule out any radiological involvement around the pins. In addition, patients with major pin tract infection (Chicketts grade 4 and above) had an immediate check $x$-ray done to rule out radiological involvement. These patients were determined by the presence of pin loosening clinically. The collected data was analyzed using the SPSS version 20.Approval to conduct the study was sought from the Department of Orthopedic Surgery, University of Nairobi as well as Kenyatta National Hospital, Ethics and Research Committee (KNH/UON-ERC).Participants in this study or their next of kin were required to give a written informed consent.

\section{Results}

Seventy three patients (73) were recruited into the study and followed up for 6 weeks. No patient was lost to follow up as the follow up period was short and most patients were admitted in the wards for longer than the follow up period. Fifty patients (68.5\%) were male and 23 patients were female (31.5\%). The patients' age range was 18 to 64 years with a mean age of 34 years. The median age was 32 years with a standard deviation of 11 . The diagnoses of patients recruited is summarized in Table 2.

Table 2: Diagnosis of patients recruited

\begin{tabular}{|l|c|c|}
\hline Site & Number of Patients & Percentage of Total Patients \\
\hline Open Tibia-Fibular Fracture & 57 & 78.1 \\
\hline Open Femur Fracture & 10 & 13.7 \\
\hline Open Humerus Fracture & 1 & 1.4 \\
\hline Open Radius Ulna Fracture & 3 & 4.1 \\
\hline Combined Open Tibia-Fibular & 2 & 2.7 \\
\hline And Femur Fractures & & \\
\hline Totals & $\mathbf{7 3}$ & $\mathbf{1 0 0}$ \\
\hline
\end{tabular}


Table 3. Gustillo Classification of the Open Fractures

\section{Gustillo Anderson Grade of Open Fracture}

Gustillo II

Gustillo IIIA

Gustillo IIIB

Total
Number of Enrolled Patients

28

38

7

73

Table 4. Incidence of Pin Tract Infection in various fracture regions.

\begin{tabular}{|c|c|c|c|}
\hline Site & Number Enrolled & Number Infected & Percentage Infected \\
\hline $\begin{array}{l}\text { Open Tibia - Fibular } \\
\text { Fracture }\end{array}$ & 57 & 49 & 85.7 \\
\hline Open Femur Fracture & 10 & 10 & 100 \\
\hline $\begin{array}{l}\text { Combined Open Tibia } \\
\text { fibular And Femur } \\
\text { Fractures }\end{array}$ & 2 & 1 & 50 \\
\hline $\begin{array}{l}\text { Open Humerus } \\
\text { Fracture }\end{array}$ & 1 & 1 & 100 \\
\hline $\begin{array}{l}\text { Open Radius - Ulna } \\
\text { Fracture }\end{array}$ & 3 & 3 & 100 \\
\hline Totals & 73 & 64 & 87.6 \\
\hline
\end{tabular}

Table 5. The incidence of pin tract infections in the various Gustillo Classifications

\begin{tabular}{|l|c|c|c|}
\hline $\begin{array}{l}\text { Gustillo Anderson } \\
\text { Grade of Open }\end{array}$ & Number Enrolled & Number Infected & Percentage Infected \\
\hline Fracture & & & \\
\hline Gustillo II & 28 & 20 & 71.4 \\
\hline Gustillo IIIA & 38 & 37 & 97.4 \\
\hline Gustillo IIIB & 7 & 7 & 100 \\
\hline Total & $\mathbf{7 3}$ & $\mathbf{6 4}$ & $\mathbf{8 7 . 6}$ \\
\hline
\end{tabular}




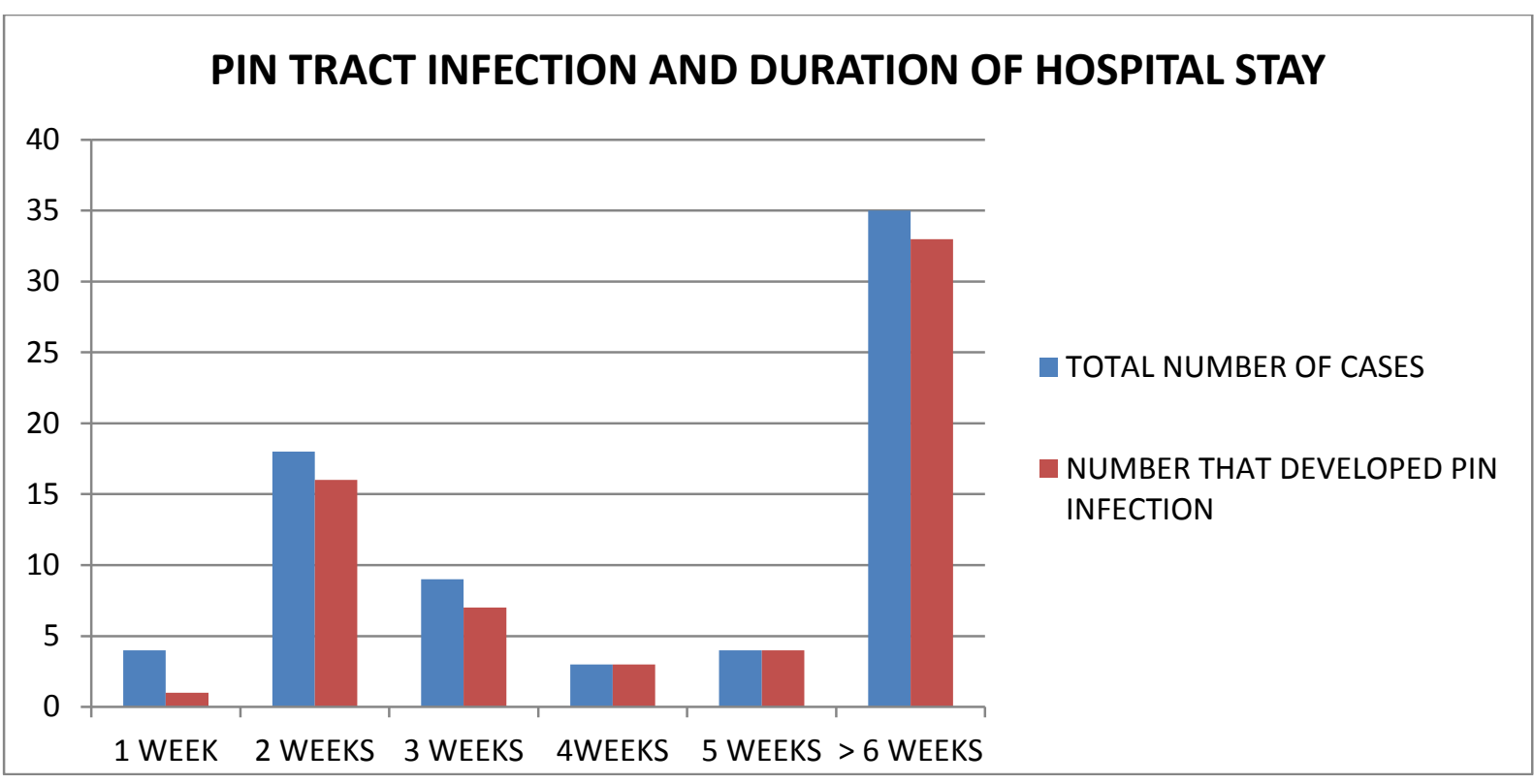

Figure 1. Pin Tract Infection ad Dulation of Stay

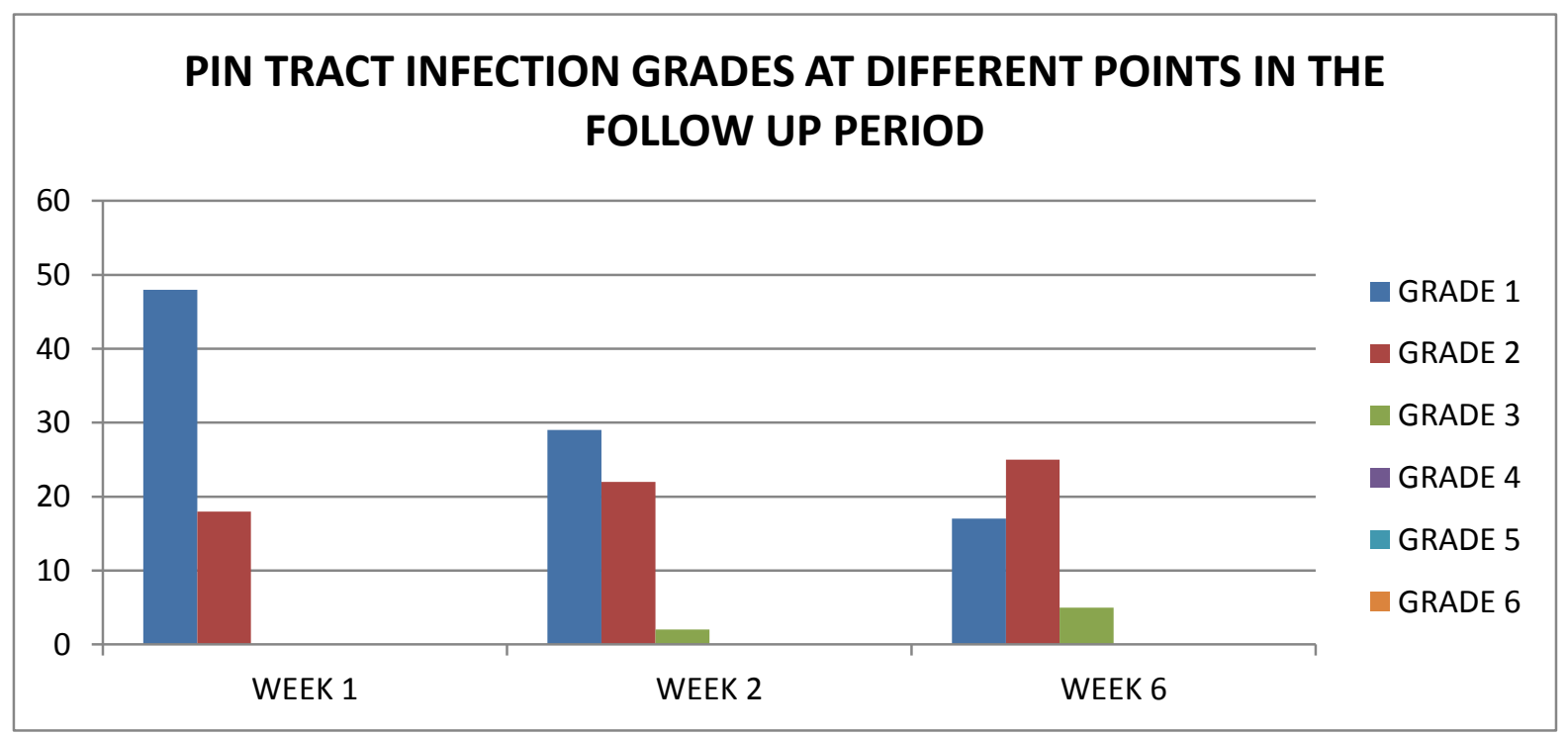

Figure 2. Pin tract infection and duration of hospital stay

Sixty-four patients (87.7\%) had pin tract infection at some point during the 6 weeks follow up; only nine patients (12.3\%) did not develop any grade of pin tract infection throughout the follow up period of 6 weeks. The incidence of pin tract infection in the various fracture regions is shown in Table 4. The pin tract infection grades at different periods of follow up are shown in Figure 1 below. The incidence of pin tract infections in the various Gustillo Classifications is shown in Table 5. The incidence of pin tract infection and duration of hospital stay is shown in Figure 2 below. The organisms responsible for pin tract infection are shown in Figure 3 below. 

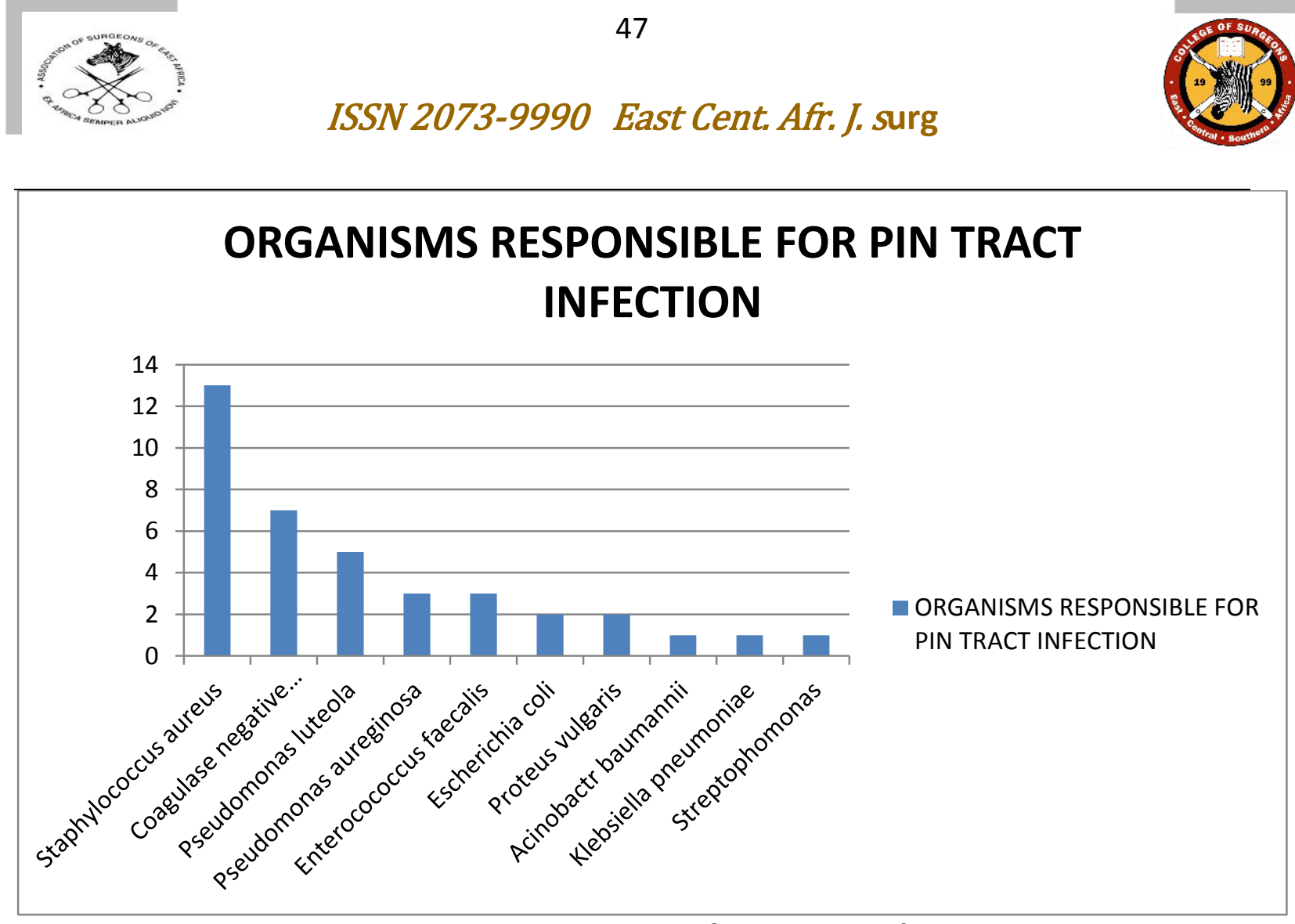

Figure 3. Organisms responsible for pin tract infection

\section{Discussion}

The incidence of pin tract infection was quite high at $87.7 \%$. This compared to a similar study done by Aronson and Tursky ${ }^{3}$ who quoted an incidence of $85 \%$ - this study involved 132 pediatric age group patients. The incidence was however significantly higher than that quoted by Parameswaran et al $^{1}$ of $11.2 \%$. His study involved 285 patients in a level 1 trauma centre but was retrospective.

Despite the high incidence, all the infections were minor - either grade 1, 2 or 3 infection based on the Checketts-Otterburn classification system. None of these infections involved the bone; all were actually soft tissue infections around the pin-sites. This may be possibly explained by the limited follow up period of only 6 weeks as bone infection may take longer to occur.

In keeping with other studies done by Antoci et al ${ }^{5}$ and Mahan et al ${ }^{6}$, Staphylococcus aureus was the commonest organism responsible for pin tract infection. Other common organisms isolated - coagulase negative staphylococci, Pseudomonas species, Enterobacter species, Escherichia coli-were also the same ones quoted by these studies.

\section{Conclusions}

The incidence of pin tract infection after uniplanar fixation of open fractures in $\mathrm{KNH}$ is high (87.7\%). Most of these infections are minor - involving soft tissues only. Staphylococcus aureus and coagulase negative staphylococci are the main causative agents of pin tract infection accounting for almost half the cases of infection. 
Recommendations

1. Better surgical technique and pin site care is needed to reduce the incidence of pin tract infection.

2. Anaerobic organisms seldom cause pin tract infection and anaerobic cover may not be necessary when treating such.

Acknowledgements

Mrs. Asaneth Nyandika of Pathologists Lancet Kenya for her analysis of the lab samples.

\section{References}

1. Parameswaran AD, Roberts CS, Seligson D, Voor M. Pin tract infection with contemporary external fixation: how much of a problem? J Orthop Trauma. 2003; 17(7):503-507.

2. Schalamon J, Petnehazy T, Ainoedhofer H, ZwickEB, Singer G, Hoellwarth ME. Pin tract infection with external fixation of pediatric fractures. J Pediatr Surg. 2007 Sep; 42(9):1584-1587.

3. Aronson J, Tursky EA. External fixation of femur fractures in children. J PediatrOrthop. 1992 Mar-Apr; 12(2):157-163.

4. Norrish AR, Lewis CP, Harrison WJ. Pin tract infection in HIV-positive and HIVnegative patients with open fractures treated by external fixation: a prospective, blinded, case-controlled study. J Bone Joint Surg Br. 2007 Jun; 89(6):790-793.

5. V Antoci, Craig M, ValenAntociJr, Ellen M. Pin tract infection during limb lengthening using external fixation. American Journal Orthop. 2008; 37(9): E150-E154.

6. Mahan J, Seligson D, Henry SI, Hynes P, Dobbins J. Factors in pin tract infections. Orthopaedics 1991; 14(3):305-308.

7. Checketts RG, MacEachern AG, Otterburn M. Pin tract infection and the principles of pin-site care. In: Goldberg A, De Bastiani A, Graham Apley A, editors: Orthofixexternal fixation in trauma and orthopaedics. Berlin, Heidelberg, New York: Springer; 2000 pp $97-103$.

8. William G. Cochran. The estimation of sample size. In Cochran, Editor. Sampling Techniques. New York: Wiley \& Sons; 1977. Pg $75-76$. 